\title{
The Role of the Pap Smear Diagnosis: Atypical Glandular Cells (AGC)
}

\author{
Chiung-Ru Lai ${ }^{1,2}$, Chih-Yi Hsu ${ }^{1,2}$ and Anna Fen-Yau Li ${ }^{1,2}$ \\ ${ }^{1}$ Department of Pathology and Laboratory Medicine, \\ Taipei Veterans General Hospital, \\ ${ }^{2}$ School of Medicine, National Yang-Ming University, Taipei, \\ Taiwan
}

\section{Introduction}

Glandular lesions of the female genital tract have always been a challenge for pathologists. The precise cytological diagnosis of these lesions is difficult because of their inherent complexity, as well as the lack of experience of many cytopathologists in this field.

The term atypical glandular cells of undetermined significance (AGUS) was first introduced at the 1988 Bethesda Conference (National Cancer Institute Workshop, 1989) and defined as morphologic changes in glandular cells beyond those suggestive a benign reactive process, but insufficient for the interpretation of adenocarcinoma. In the 2001 Bethesda System (TBS 2001) (Solomon, 2002), the term has been changed to better reflect current knowledge and understanding of glandular neoplasia. The category has been defined and renamed "atypical glandular cells" (AGC), with the subclassifications "not otherwise specified" (AGC-NOS) and "favor neoplastic" (AGC-FN). The cell type of origin, endocervical or endometrial, should be addressed whenever possible. Adenocarcinoma in situ has been separated as another distinct category of diagnosis.

In 2006, the American Society for Colposcopy and Cervical Pathology (ASCCP) released consensus guidelines for the management guidelines for the management of AGC (Wright, 2007). The guidelines emphasized combined colposcopy and endocervical sampling was recommended for all women across all subcategories of AGC, with the addition of endometrial sampling for women over 35. So, since 2006, more comprehensive evaluations were applied for these women. Recent studies concerning the follow-up outcomes of AGC revealed more patients with precancerous or malignant diseases of different sites ranging from the exo-cervix, endocervix, endometrium, fallopian tube, ovary and even extra-genital organs (Behtash, 2007; Duska, 1998; Jeng, 2003; Koonings, 2001; Lai, 2008; Manetta, 1999; Mood, 2006; Soofer, 2000). Since the introduction of Pap smear screening, the incidence of cervical squamous cell carcinoma has been dramatically declined but the relative incidence of glandular cancer has been increased. However, the sensitivity of detecting cervical glandular precancerous or cancer lesions is much less than that of the squamous lesions making cervical glandular cancer prevention remains a challenge and problem to be solved 
(Koss, 1989; Wingo, 2003). So, our ability to recognize and diagnose AGC-NOS or AGC-FN is very important. After correct triage of patients with AGC Pap smears, early treatment of these lesions may be achieved. The protective effects of cytologic screening for glandular lesions can be then improved.

In our previous study (Lai, 2008), it supported the view that a diagnosis of AGC is clinically significant by the 2001 Bethesda System, especially the AGC-FN category. The subclassification of AGC is important and demanded in the diagnosis of Pap smears. Addressing the cell origin of endometrium, although being found no statistically significant difference, it showed a more common significant pathology outcome. Since then, we still followed the 2001 Bethesda System to subclassify and address the cell origin in AGC Pap smears. As to management protocol, we strongly recommend following the ASCCP consensus guidelines. In the current retrospective study of 9 years experience, histological follow-up results obtained and paired to the corresponding cytology interpretation, and the results further enhanced the importance of the role of the Pap smear diagnosis of AGC in screening and diagnosing the precancerous and cancer lesions.

\section{Materials and methods}

A retrospective review of the archives of the Department of Pathology, Taipei Veterans General Hospital, from January 2002 to December 2010 identified 234 smears diagnosed as AGC with at least 6 months follow-up. All of the Pap smears since January 2002 were diagnosed and classified according to the 2001 Bethesda System criteria at the time of diagnosis. If cellular findings suggestive of endometrial glandular or stromal cells were noted, the description of "endometrial origin" would be made in the space of "educational notes and suggestion" in the cytologic report. An adequate evaluation for AGC Pap smears suggested by the ASCCP included a colposcopy with or without cervical biopsy, endocervical curettage and an endometrial sampling, especially in those patients in whom endometrial origin was addressed in the Pap test. In addition, those patients who received other diagnostic or treatment procedures such as conization, loop electrosurgical excision procedure (LEEP) or hysterectomy were also included in this study. The most abnormal histology was considered to be the outcome. Patients who failed to receive the management described even with multiple repeated pap smears were excluded in the evaluation.

The clinical information of patient, such as age, menopausal status, hormonal replacement therapy status, tamoxifen use status, and presence of abnormal bleeding were collected from medical record. Pathology findings of endometrial biopsy were categorized as benign, precursors (high grade squamous intra-epithelial lesion, endocervical adenocarcinoma in situ, endometrial atypical complex hyperplasia), and malignant. The precursors and malignant pathology results are defined as abnormal pathology. Based on cyto-histological and available clinical data, we made meticulous description of the cytological findings including atypical glandular cells themselves and the background pattern and statistical analyses on the different subclassifications of AGC by using Chi-square test and multivariate logistic regression. A $\mathrm{P}$ value $<0.05$ was considered to be statistically significant. 


\section{Results}

\subsection{Pathology results}

From a total of 228,451 cervicovaginal cytologic specimens within a 9-year period from January 2002 to December 2010, a total of 234 (0.1\%) AGC Pap smears were identified. The age distribution ranged from 27 to 93 years (median 49). All were conventional Pap smears and primarily carried out for cervical cancer screening. 190 of 234 (81\%) cases with adequate histologic evaluation were included in this study. (Table 1)

\begin{tabular}{lll} 
AGC subtype & Number & Histologic follow-up (\%) \\
\hline AGC-NOS & 197 & $157(80 \%)$ \\
AGC-FN & 37 & $33(89 \%)$ \\
Total & 234 & $190(81 \%)$ \\
\hline
\end{tabular}

AGC: atypical glandular cells

AGC-NOS: atypical glandular cells, not otherwise specified

AGC-FN: atypical glandular cells, favor neoplastic

Table 1. Histologic follow-up rates by AGC subtype

Adequate initial evaluation for AGC Pap smears suggested by the ASCCP included a colposcopy with or without cervical biopsy, endocervical curettage and an endometrial sampling, especially in those patients endometrial origin was addressed in the Pap test. Abnormal histology of precursors and invasive lesions were found in 76 patients $(40 \%)$ (Table 2) Final pathology results included 37 endometrial adenocarcinomas, 6 endocervical adenocarcinomas, 1 cervical squamous cell carcinoma, 1 endometrial malignant mixed Mullerian tumor (MMMT), 3 ovarian carcinomas, 3 colon-rectal adenocarcinomas, 1 fallopian tube adenocarcinoma, 4 endocervical adenocarcinoma in situ, 2 endocervical glandular dysplasia, 6 high grade squamous intraepithelial lesion (HSIL), and 11 endometrial complex hyperplasia. Invasive diseases, accounting for $28 \%$ (53 of 190) were much more common than precursors, $12 \%$ (23 of 190). All of the patients with significant pathology received definitive treatment, including complete staging surgery for those harboring invasive neoplastic diseases.

There were 83 smears sub-classified as AGC-NOS; 75 as AGC-NOS, endometrial origin (EM); 21 as AGC-N, endometrial origin (EM); 11 as AGC-N. The subgroup of AGC-N, EM had the highest rate of abnormal pathology, followed by AGC-NOS, EM, AGC-N and AGCNOS; 18 of $21(86 \%), 30$ of $75(40 \%), 4$ of $11(36 \%)$ and 24 of $83(29 \%)$, respectively. The difference was significant. $(\mathrm{P}<0.001)$ Women with AGC-N were more likely to have significant pathology (22 in $32(69 \%)$ ) compared with those with AGC-NOS (54 in 158 $(34 \%))$. It was statistically significant. $(\mathrm{P}<0.001)$ The endometrial origin addressed cases had more abnormal pathology results than those not being addressed, 48 of 96 (50\%) v.s. 28 of 94 $(30 \%)$. $(\mathrm{P}=0.004)$ (Table 3) 
Histologic results

Cases (\%)

Benign

$114(60 \%)$

Abnormal

$76 \quad(40 \%)$

Invasive lesions

$53(28 \%)$

Cervical cancer

7

Adenocarcinoma

6

Squamous cell carcinoma

1

Endometrial cancer

38

Adenocarcinoma

37

Malignant mixed Müllerian tumor

1

Extra-uterine malignancies

8

Ovary carcinoma

3

Rectal cancer

4

Tubal carcinoma

1

Precursor lesions

$23(12 \%)$

Endocervical glandular dysplasia

2

Endocervical adenocarcinoma in situ

4

High grade squamous intraepithelial lesion

6

Endometrial complex hyperplasia (including atypical)

11

Table 2. Final Histologic results of 190 patients with AGC Pap smears 


N Benign Abnormal $P$

Diagnostic category

\begin{tabular}{|c|c|c|c|}
\hline AGC-NOS, EM & 75 & $45(60 \%)$ & $30(40 \%)$ \\
\hline AGC-NOS & 83 & $59(71 \%)$ & $24(29 \%)$ \\
\hline AGC-FN, EM & 21 & $3(14 \%)$ & $18(86 \%)$ \\
\hline AGC-FN & 11 & 7 (64\%) & $4(36 \%)$ \\
\hline
\end{tabular}

EM

\begin{tabular}{|c|c|c|c|}
\hline Address & 96 & $48(50 \%)$ & $48(50 \%)$ \\
\hline Not address & 94 & $66(70 \%)$ & $28(30 \%)$ \\
\hline
\end{tabular}

Favor neoplastic

Yes

No

Total cases
32

158

190
$10(31 \%)$

$104(66 \%)$

$114(60 \%)$

$22(69 \%)$ $<0.001^{1}$

${ }^{1}$ chi-square test

EM: endometrial origin

Table 3. Abnormal histologic results in different AGC subtypes

\subsection{Cytologic findings and differential diagnoses}

Degenerative atypical endometrial glandular cells admixed with endometrial debris indicated endometrial origin, The endometrial debris distributed along the smearing direction (Figure 1-3) was characterized by watery diatheses, foamy histiocytes, degenerative necrotic debris and phagocytosis (Figure 4). Some or all of the above findings were observed in 1 fallopian tube adenocarcinoma , 25 endometrial adenocarcinomas and 1 MMMT but none of the cervical lesions and other extra-uterine cancers. 


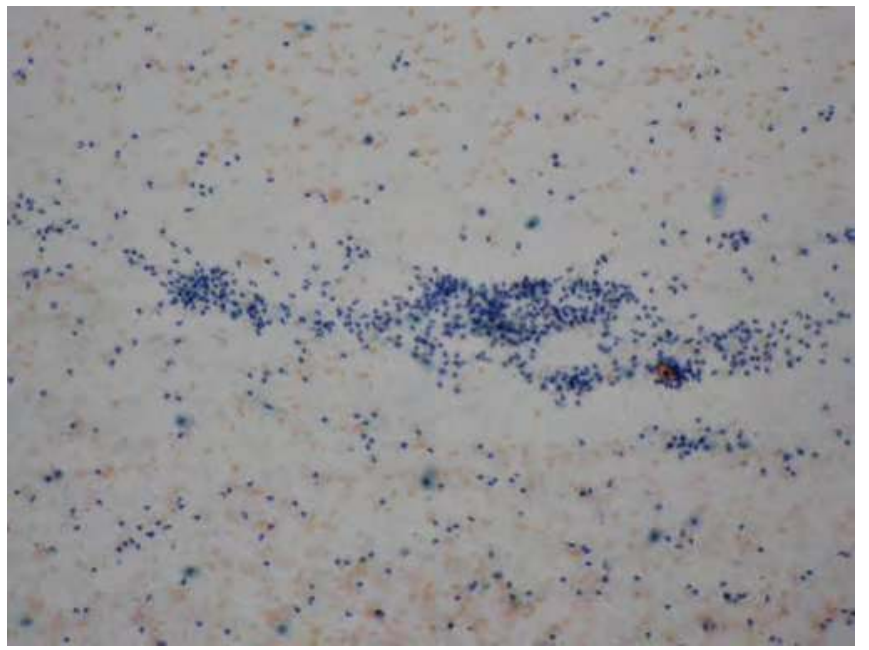

Fig. 1. The endometrial debris distributed along the smearing direction in the background. (Papanicolaou stain, 100x)

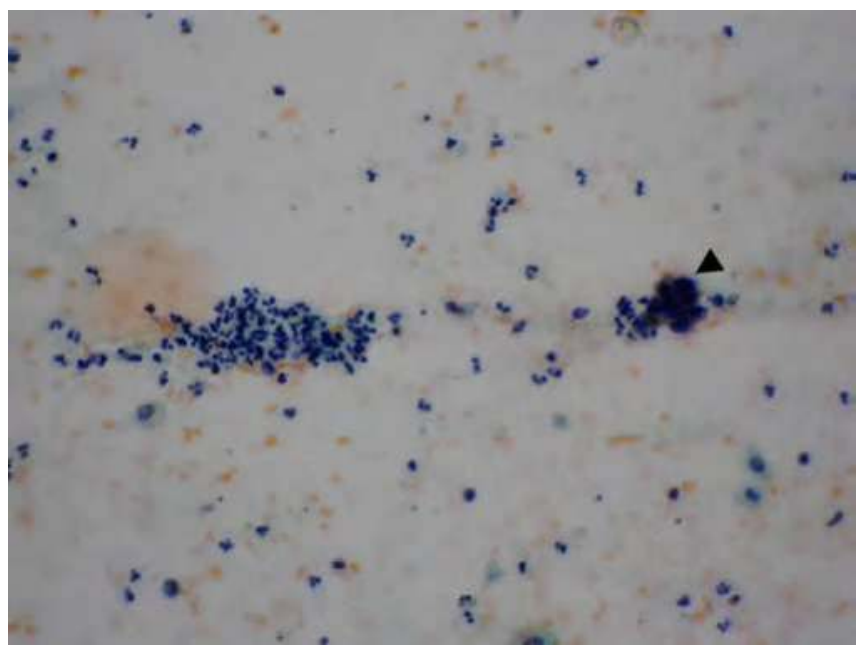

Fig. 2. Degenerative atypical endometrial glandular cells, favor neoplastic (arrow head), admixed with endometrial debris. The final pathology turned out to be an endometrioid adenocarcinoma, grade II. (Papanicolaou stain, 200x) 


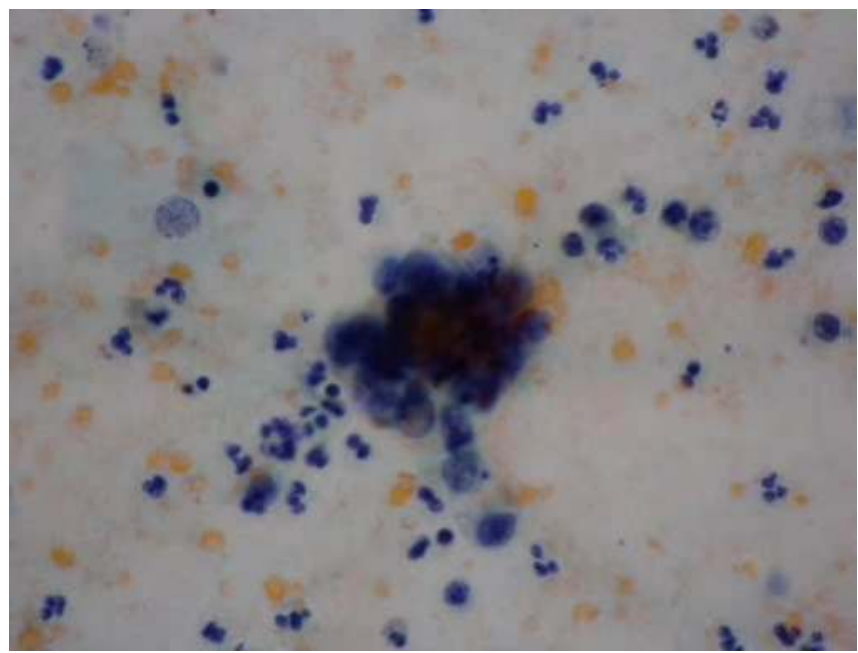

Fig. 3. The higher magnification showed tight cluster of atypical endometrial glandular cells with degeneration, high N/C ratio, three-dimensional structure, and small faint nucleoli. These features fall short of diagnosing an adenocarcinoma directly, either in quantity or quality. (Papanicolaou stain, 400x)

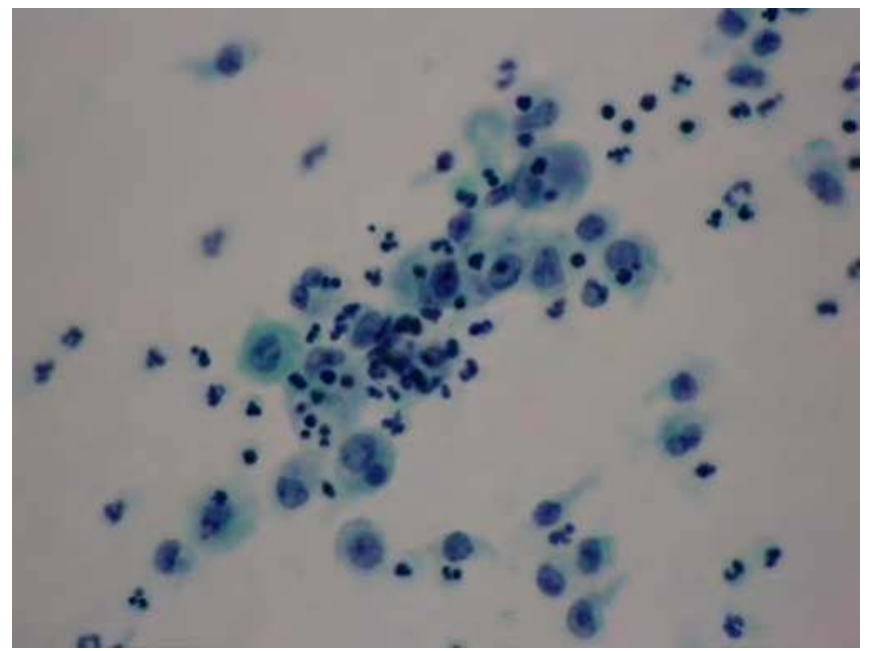

Fig. 4. The endometrial debris was characterized by watery diatheses, foamy histiocytes, degenerative necrotic debris and phagocytosis. It was very specific for endometrial lesions. (Papanicolaou stain, 400x)

The distribution pattern, along the smearing direction, was very characteristic for this kind of debris indicating shedding from endometrium instead of endocervix. However, it would disappear in the fluid-based preparations. In addition, mucin substance was always absent in the endometrial debris. On the contrary, we noticed that a characteristic finding 
consisting of necrosis and a mucinous background resembling the pattern seen in ileal conduit urine was an indicator suggestive of endocervical adenocarcinoma (Figure 5-8).

This feature was seen in 3 of the 6 endocervical adenocarcinomas but none of the other cancers.

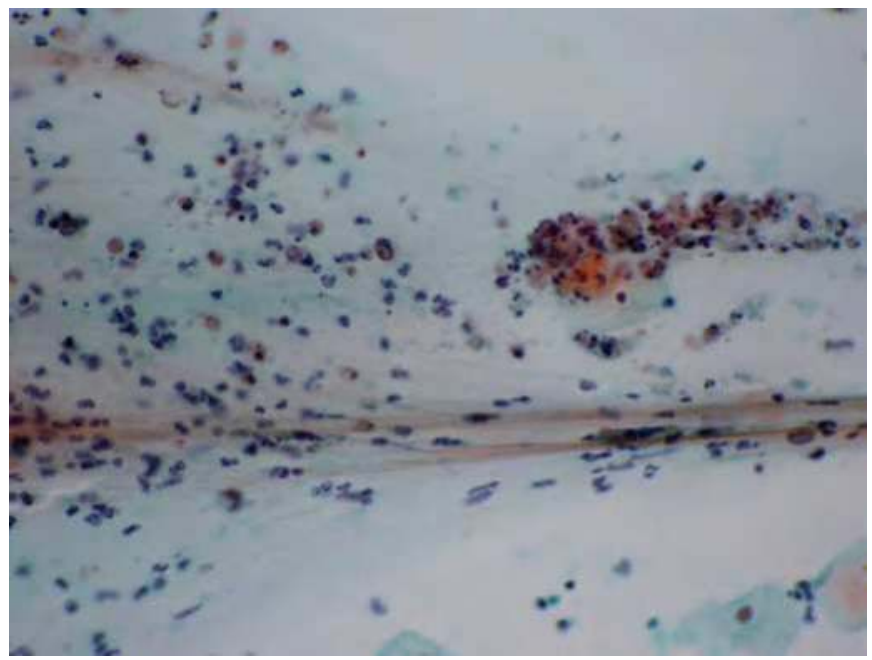

Fig. 5. Background of mucin streaks admixed with necrotic mucous cells resembling those of an ileal conduit urine specimen. (Papanicolaou stain, 200x)

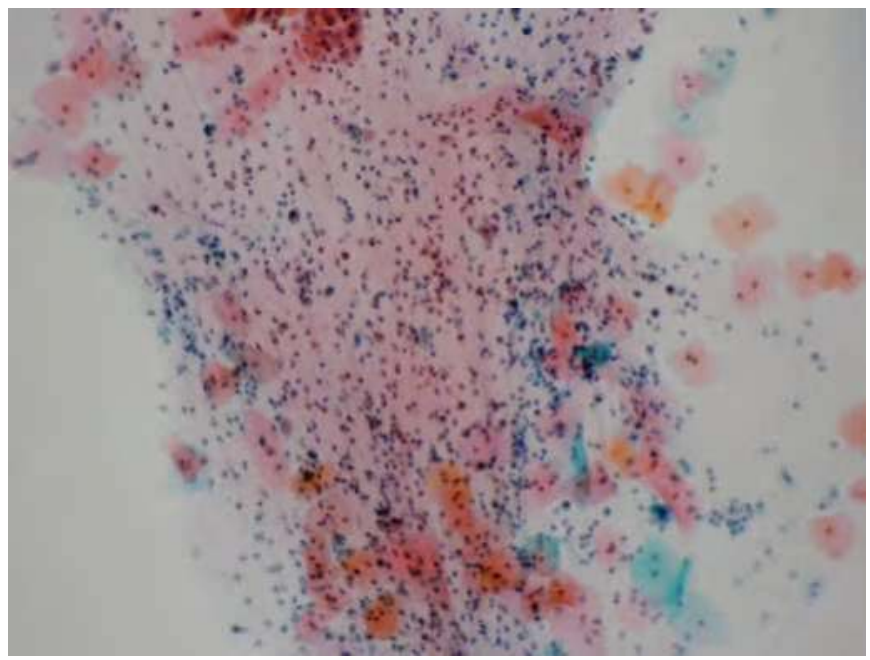

Fig. 6. Background mucin streaks are very thick and have characteristic color and distribution. (Papanicolaou stain, 100x) 


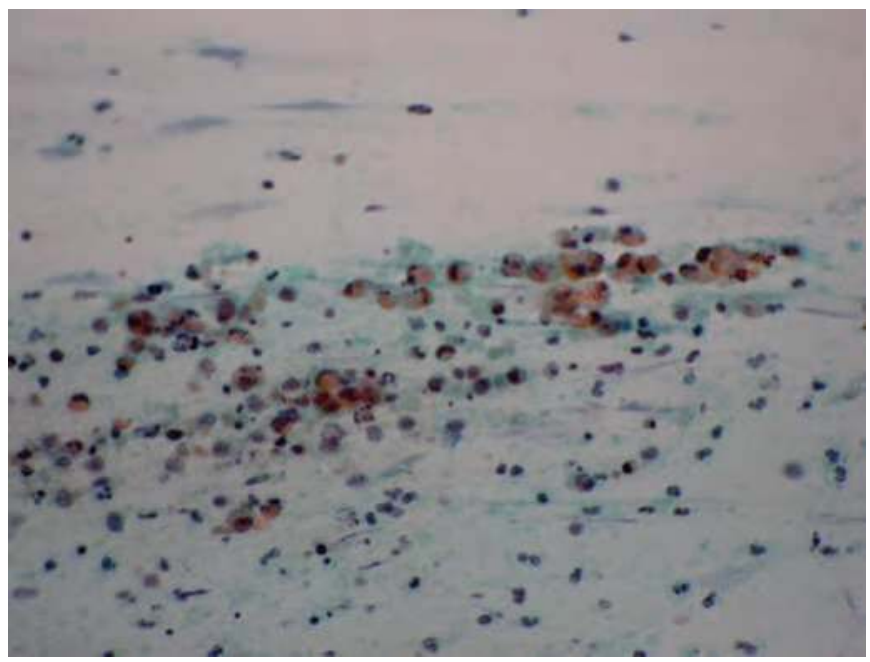

Fig. 7. Ileal conduit urine like features contained abundant degenerative glandular mucous cells and debris. (Papanicolaou stain, 200x)

Recognizing this dirty mucin background would be very important in the interpretation of AGC Pap smears and helped the clinicians successfully found the primary site of cancers.

Endometrial debris admixed with atypical endometrial glandular cells would be seen not only in the cancer patients but also in benign lesions, such as endometrial polyp and intrauterine contraceptive device (Figure 9-10). Clinical information is very important to avoid over diagnosis.

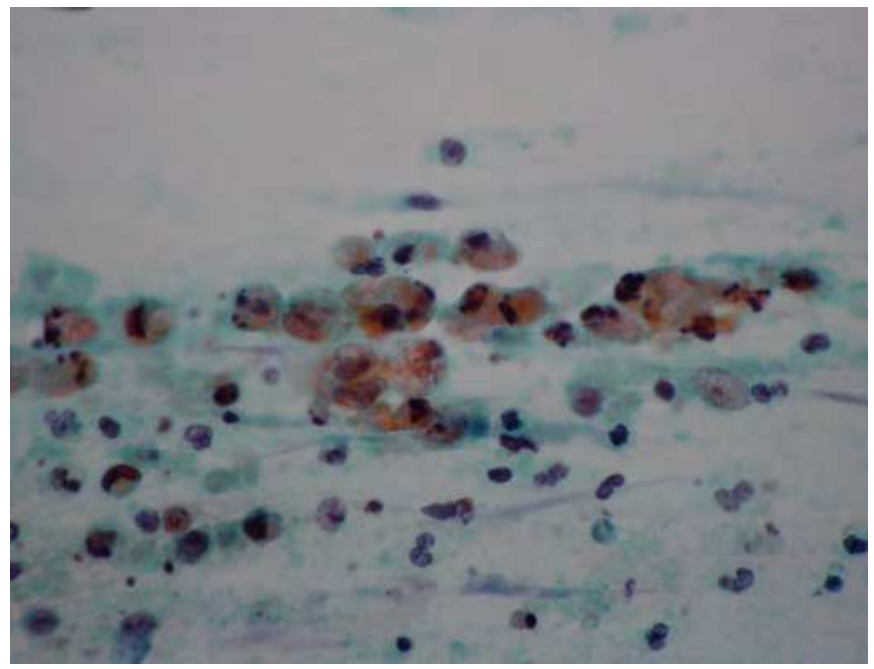

Fig. 8. These degenerative mucous cells had small eccentric hyperchromatic nuclei and abundant mucous cytoplasm indicating mucinous glandular origin. (Papanicolaou stain, 400x) 


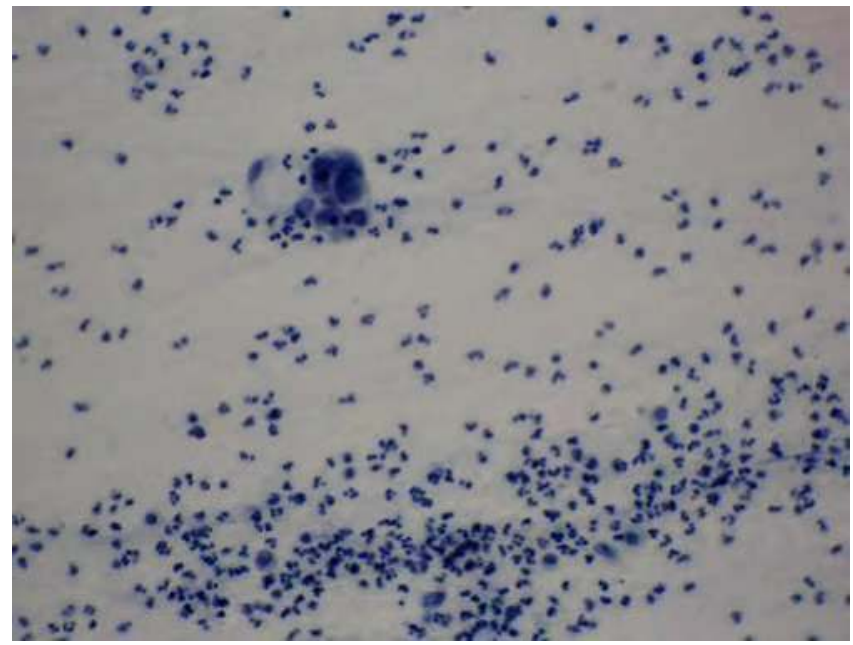

Fig. 9. Degenerative atypical endometrial glandular cells and endometrial debris were noted in a smear of patient with intra-uterine contraceptive device (IUD). Originally, the diagnosis of AGC-NOS, EM was given without knowing the IUD situation. (Papanicolaou stain, 200x)

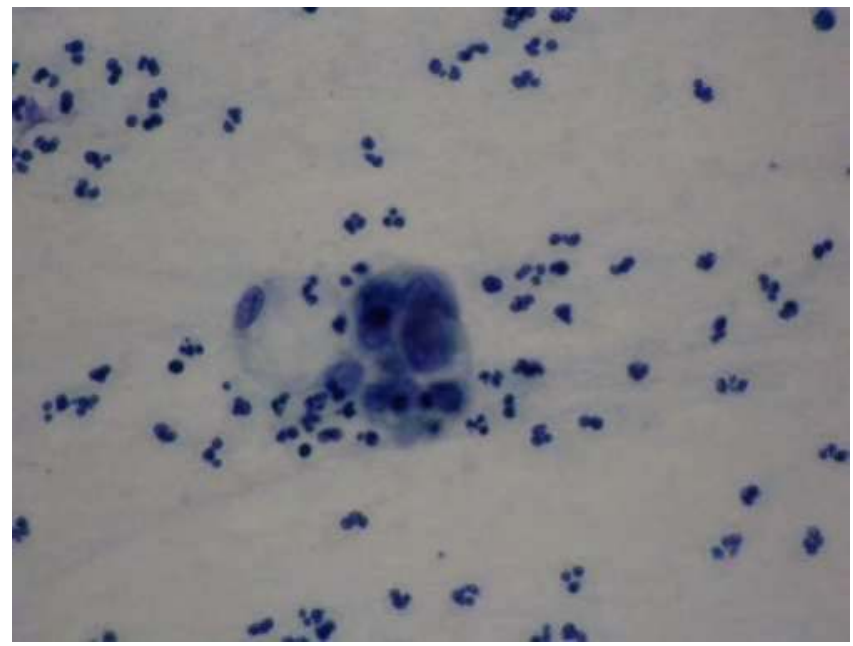

Fig. 10. Higher magnification showed small three-dimensional group of endometrial glandular cells with characteristic cytoplasmic vacuolation and slightly enlarged hyperchromatic nuclei. (Papanicolaou stain, 400x)

The major differential diagnoses of atypical endocervical glandular cells include adenocarcinoma in situ (Figure 11), tubal metaplasia (Figure 12) and lower uterine segment cells (Figure 13). When the lesion is adequately sampled and the abnormal cells are well visualized both quantitatively and qualitatively, the diagnosis will be no problem in most circumstances. Otherwise, these look-alike entities should be taken into the list of differential diagnoses. 


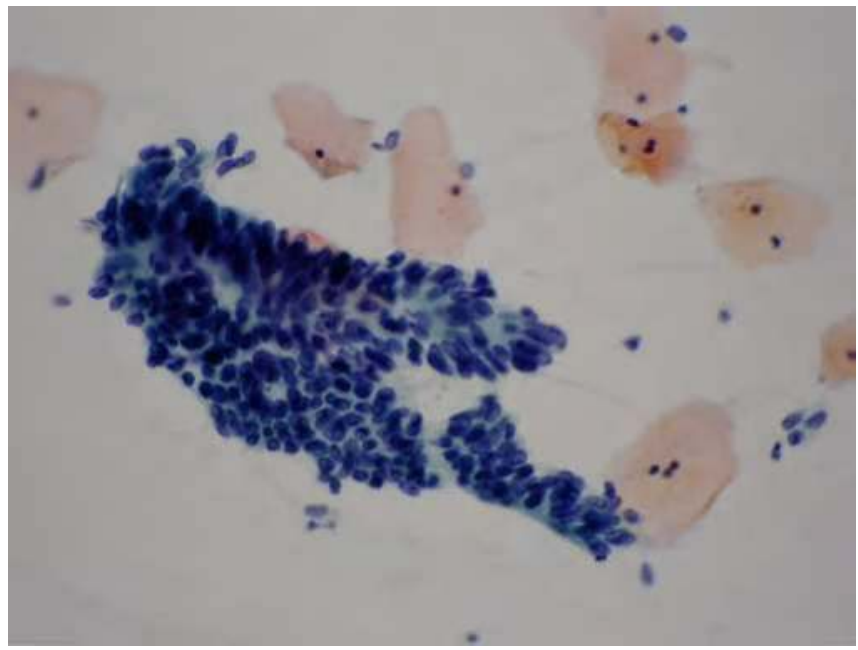

Fig. 11. Super-crowded endocervical glandular cells presenting pseudostratification and feathering edge. The nuclei are elongated and hyperchromatic with high $\mathrm{N} / \mathrm{C}$ ratio.

Nucleoli are absent. However, only two fragments were seen. The diagnosis of AGC-FN was made. Final histology proved to be endocervical adenocarcinoma in situ. (Papanicolaou stain, 200x)

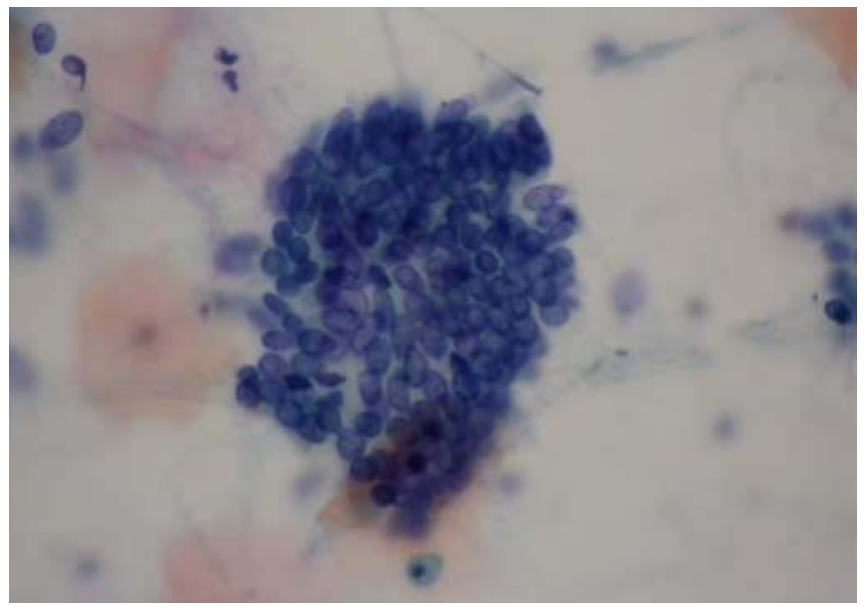

Fig. 12. Tubal metaplasia can closely mimic adenocarcinoma in situ. However, on close inspection, the abnormalities, such as crowding, nuclear elongation, hyperchromasia, and stratification are less severe. Locating terminal bars or cilia can help in confirmation, but they could not be identified in the smear we examined. The original diagnosis for this case was AGC-NOS, endocervical origin. (Papanicolaou stain, 400x) 


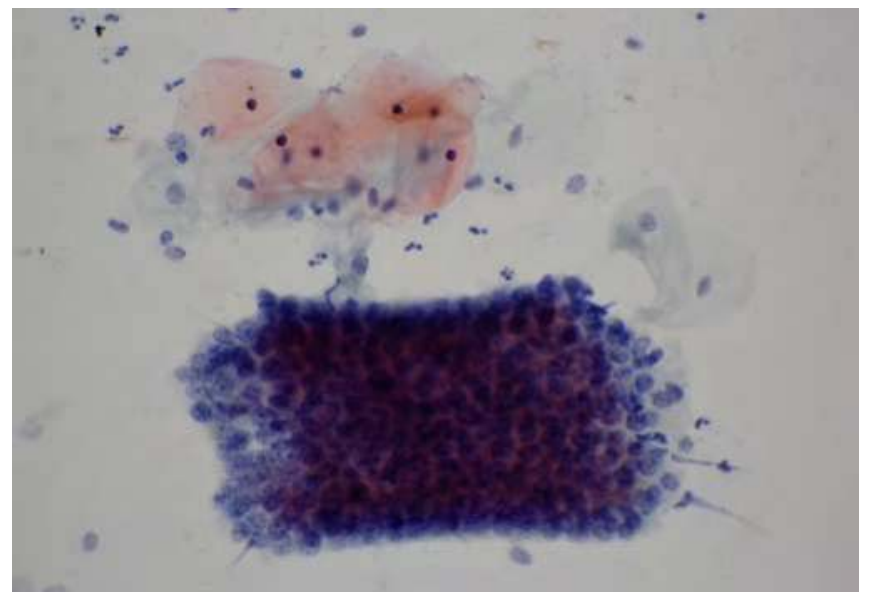

Fig. 13. Lower uterine segment cells were composed of tightly packed uniform glandular cells in crowded honeycomb appearance. A stromal element is usually present in the surrounding area, which is an aid in the differential diagnosis. However, the stromal component is absent in the present case, the original diagnosis was AGC-NOS, cell origin also not otherwise specified. (Papanicolaou stain, 400x)

\section{Discussion}

The TBS was first introduced in 1988 for reporting cervical/vaginal cytology findings (National Cancer Institute Workshop, 1989). Revisions were made in 2001 to improve its sensitivity and specificity. In terms of categories of atypical glandular cells, In the 1988 version these cells were defined as "atypical glandular cells of undetermined significance (AGUS)". In the current 2001 version (Solomon, 2002), this nomenclature has changed to "atypical glandular cells, not otherwise specified (AGC-NOS)" and "atypical glandular cells, favor neoplastic (AGC-FN). Subclassification of cell origin (endocervical, endometrial, or not otherwise specified) should be done whenever possible. The TBS 2001 reporting system was proved to be better for detecting underlying gynecological lesions, including precursors and invasive malignant diseases in many reports (Behtash, 2007; Duska, 1998; Jeng, 2003; Koonings, 2001; Lai, 2008; Manetta, 1999; Mood, 2006; Soofer, 2000). The incidence of abnormal pathology ranged from $8.2 \%$ to $53 \%$. Most studies defined abnormal pathology as precursors and invasive malignant diseases. Low grade squamous intra-epithelial lesions (LSIL) were excluded. The invasive malignancies may originate not only from uterine cervix and corpus but also extra-uterine organs, such as fallopian tube, ovary, colon and rectum. In this current report, we found that endometrial cancer was by far the most common malignant disease, 38 in 53 cases (72\%), diagnosed in the AGC smears (Table 2). This was the highest data ever reported. The reason may be that since our previous observation of the importance of endometrial debris (Lai, 2008), the screeners paid much attention to this kind of cytology findings. The sensitivity of reporting endometrial debris increased and then detected more endometrial cancers.

The concept of subclassification of AGC to NOS and FN categories as an important predictor for the risk of abnormal pathology was further supported in the current study (Table 3). The 
subgroup of AGC-N, EM had the highest rate of abnormal pathology, followed by AGCNOS, EM, AGC-N and AGC-NOS; 18 of 21 (86\%), 30 of $75(40 \%), 4$ of 11 (36\%) and 24 of 83 $(29 \%)$, respectively. The difference was significant. $(\mathrm{P}<0.001)$ Women with AGC-N were more likely to have significant pathology (22 in $32(69 \%))$ compared with those with AGCNOS (54 in $158(34 \%))$. It was statistically significant. $(\mathrm{P}<0.001)$ The results were in accordance with other previous studies (Adhya, 2009; Behtash, 2007; Sawangsang, 2011; Westin, 2008; Zhao, 2009). They also confirmed the high risk nature of AGC smears. They have consistently demonstrated that the rate of abnormal pathology was significantly high if the AGC smears further classified as favoring neoplasia (41\%-70\%).

Since we have observed the importance of endometrial debris in our previous report (Lai, 2008), in the current study, only endometrial origin smears were calculated separately in order to strengthen the importance of this factor. The endocervical and not otherwise specified origins were counted together. The subgroup of AGC-N, EM had the highest rate of abnormal pathology, followed by AGC-NOS, EM, AGC-N and AGC-NOS; 18 of 21 (86\%), 30 of $75(40 \%), 4$ of $11(36 \%)$ and 24 of $83(29 \%)$, respectively. The difference was significant. $(\mathrm{P}<0.001)$ The endometrial origin addressed cases had more abnormal pathology results than those not being addressed, 48 of $96(50 \%)$ v.s. 28 of $94(30 \%)$. ( $\mathrm{P}=0.004)$ (Table 3) The results further confirmed the importance of cell origin of AGC, especially the endometrial origin. The predictive value of background endometrial debris such as histiocytes for endometrial pathology in Pap smears has been a subject of controversy. Some studies have suggested a significant finding but the others didn't (Iavazzo, 2008; Koss, 1962; Nassar, 2003; Ng, 1974; Nguyen, 1998; Wen, 2003). The controversy is understandable, because the biopsy rate and the yield of endometrial neoplasm in these patients were relatively low in the past. According to Browne's study (Browne, 2005), they found a 5-fold increase in the frequency with which endometrial cells were reported after the implementation of the TBS 2001. This then resulted in $25.2 \%$ of biopsies, a 1.3 fold increase in the overall number of tissue proof. Our another study (Lai, in press) of the importance of endometrial debris also revealed similar results. It showed that even in the absence of AGC, the presence of endometrial debris rather than the menopausal status was more related to the rate of biopsy procedure and a malignant pathology result. Degenerative necrotic debris is a significant risk factor for endometrial pathology, regardless of the presence or absence of AGC. Although the cervical screening program is not designed to detect endometrial lesions, early detection of any such cases is possible and is a bonus to be beneficial for these patients by identifying the significant degenerative endometrial debris in the Pap smears. Finally, another characteristic dirty mucinous background cytomorphology indicating endocervical adenocarcinoma observed in our series, being limited number of cases at present, will be continuously studied to investigate its sensitivity and specificity.

\section{Conclusion}

In the current study, AGC smears were associated with a high prevalence of abnormal pathology, including precursors and malignant diseases. Furthermore, the results of separations between "not otherwise specified" v.s. "favor neoplastic' and "endometrial origin" was statistically significant. Endometrial cancers were the most common neoplasm in the AGC patients. The above findings supported the TBS 2001 for subcategories of AGC 
and subclassifications of cell origins and the appropriate management algorithm of the guidelines of ASCCP 2006.

\section{References}

Adhya, A.K., Mahesha, V., Srinivasan, R., Nijhawan, R., Rajwanshi, A., Suri, V., \& Dhaliwal, L.K. (2009). Atypical glandular cells in cervical smears: histological correlation and a suggested plan of management based on age of the patient in a low-resource setting, Cytopathology, Vol. 20, No. 6, (December 2009), pp. 375-379, ISSN 1365-2303

Behtash, N., Nazari, Z., Fakhrejahani, F., Khafaf, A., \& Azar, E.G. (2007). Clinical and histological significance of atypical glandular cell on Pap smear, Australian and New Zealand Journal of Obstetrics and Gynaecology, Vol. 47, No. 1, (February 2007), pp. 4649, ISSN 0004-8666

Browne, T.J., Genest, D.R., \& Cibas, E.S. (2005). The clinical significance of benign-appearing endometrial cells on a Papanicolaou test in women 40 years or older, American Journal of Clinical Pathology, Vol. 124, No. 6, (January 2006 ), pp. 834-837, ISSN 00029173

Duska, L.R., Flynn, C.F., Chen, A., Whall-Strojwas, D., \& Goodman, A. (1998). Clinical evaluation of atypical glandular cells of undetermined significance on cervical cytology, Obstetrics and Gynecology, Vol. 91, No. 2, (February 1998), pp. 278-282, ISSN 0029-7844

Iavazzo, C., Kalmantis, K., Ntziora, F., Balakitsas, N., \& Paschalinopoulos, D. (2008). Detection of large histiocytes in pap smears: role in the prediction of endometrial pathology?, Bratislavske Lekarske Listy, Vol. 109, No. 11, (February 2009), pp. 497498, ISSN 0006-9248

Jeng, C.J., Liang, H.S., Wang, T.Y., Shen, J., Yang, Y.C., \& Tzeng, C.R. (2003). Cytologic and histologic review of atypical glandular cells (AGC) detected during cervical cytology screening, Int J Gynecol Cancer, Vol. 13, No. 4, (August 2003), pp. 518-521, ISSN 1048-891X

Koonings, P.P., \& Price, J.H. (2001). Evaluation of atypical glandular cells of undetermined significance: is age important?, American Journal of Obstetrics and Gynecology, Vol. 184, No. 7, (June 2001), pp. 1457-1459; discussion 1459-1461, ISSN 0002-9378

Koss, L.G. (1989). The Papanicolaou test for cervical cancer detection. A triumph and a tragedy, JAMA, Vol. 261, No. 5, (February 1989), pp. 737-743, ISSN 0098-7484

Koss, L.G., \& Durfee, G.R. (1962). Cytologic diagnosis of endometrial carcinoma. Result of ten years of experience, Acta Cytologica, Vol. 6, No., (November 1962), pp. 519-531, ISSN 0001-5547

Lai, C.R., Hsu, C.Y., Tsay, S.H., \& Li, A.F. (2008). Clinical significance of atypical glandular cells by the 2001 Bethesda System in cytohistologic correlation, Acta Cytologica, Vol. 52, No. 5, (October 2008), pp. 563-567, ISSN 0001-5547

Lai, C.R., Hsu, C.Y., \& Li, A.F. (in press). Degenerative necrotic endometrial debris in Pap smear: The role in the prediction of endometrial pathology, American Journal of Clinical Pathology, (in press), ISSN: 0002-9173

Manetta, A., Keefe, K., Lin, F., Ahdoot, D., \& Kaleb, V. (1999). Atypical glandular cells of undetermined significance in cervical cytologic findings, American Journal of Obstetrics and Gynecology, Vol. 180, No. 4, (April 1999), pp. 883-888, ISSN 0002-9378 
Mood, N.I., Eftekhar, Z., Haratian, A., Saeedi, L., Rahimi-Moghaddam, P., \& Yarandi, F. (2006). A cytohistologic study of atypical glandular cells detected in cervical smears during cervical screening tests in Iran, Int J Gynecol Cancer, Vol. 16, No. 1, (February 2006), pp. 257-261, ISSN 1048-891X

Nassar, A., Fleisher, S.R., \& Nasuti, J.F. (2003). Value of histiocyte detection in Pap smears for predicting endometrial pathology. An institutional experience, Acta Cytologica, Vol. 47, No. 5, (October 2003), pp. 762-767, ISSN 0001-5547

National Cancer Institute Workshop (1989). The 1988 Bethesda System for reporting cervical/vaginal cytological diagnoses. , JAMA, Vol. 262, No. 7, (August 1989), pp. 931-934, ISSN 0098-7484

Ng, A.B., Reagan, J.W., Hawliczek, S., \& Wentz, B.W. (1974). Significance of endometrial cells in the detection of endometrial carcinoma and its precursors, Acta Cytologica, Vol. 18, No. 5, (September 1974), pp. 356-361, ISSN 0001-5547

Nguyen, T.N., Bourdeau, J.L., Ferenczy, A., \& Franco, E.L. (1998). Clinical significance of histiocytes in the detection of endometrial adenocarcinoma and hyperplasia, Diagnostic Cytopathology, Vol. 19, No. 2, (August 1998), pp. 89-93, ISSN 8755-1039

Sawangsang, P., Sae-Teng, C., Suprasert, P., Srisomboon, J., Khunamornpong, S., \& Kietpeerakool, C. (2011). Clinical significance of atypical glandular cells on Pap smears: Experience from a region with a high incidence of cervical cancer, Journal of Obstetrics and Gynaecology Research, Vol. 37, No. 6, (June 2011), pp. 496-500, ISSN 1341-8076

Solomon, D., Davey, D., Kurman, R., Moriarty, A., O'Connor, D., Prey, M., Raab, S., Sherman, M., Wilbur, D., Wright, T., Jr., \& Young, N. (2002). The 2001 Bethesda System: terminology for reporting results of cervical cytology, JAMA, Vol. 287, No. 16, (April 2002), pp. 2114-2119, ISSN 0098-7484

Soofer, S.B., \& Sidawy, M.K. (2000). Atypical glandular cells of undetermined significance: clinically significant lesions and means of patient follow-up, Cancer, Vol. 90, No. 4, (August 2000), pp. 207-214, ISSN 0008-543X

Wen, P., Abramovich, C.M., Wang, N., Knop, N., Mansbacher, S., \& Abdul-Karim, F.W. (2003). Significance of histiocytes on otherwise-normal cervical smears from postmenopausal women. A retrospective study of 108 cases, Acta Cytologica, Vol. 47, No. 2, (April 2003), pp. 135-140, ISSN 0001-5547

Westin, M.C., Derchain, S.F., Rabelo-Santos, S.H., Angelo-Andrade, L.A., Sarian, L.O., Oliveira, E., \& Zeferino, L.C. (2008). Atypical glandular cells and adenocarcinoma in situ according to the Bethesda 2001 classification: cytohistological correlation and clinical implications, European Journal of Obstetrics, Gynecology, and Reproductive Biology, Vol. 139, No. 1, (July 2007), pp. 79-85, ISSN 0301-2115

Wingo, P.A., Cardinez, C.J., Landis, S.H., Greenlee, R.T., Ries, L.A., Anderson, R.N., \& Thun, M.J. (2003). Long-term trends in cancer mortality in the United States, 1930-1998, Cancer, Vol. 97, No. 12 Suppl, (June 2003), pp. 3133-3275, ISSN 0008-543X

Wright, T.C., Jr., Massad, L.S., Dunton, C.J., Spitzer, M., Wilkinson, E.J., \& Solomon, D. (2007). 2006 consensus guidelines for the management of women with abnormal cervical screening tests, J Low Genit Tract Dis, Vol. 11, No. 4, (October 2007), pp. 201222, ISSN 1089-2591 
Zhao, C., Florea, A., Onisko, A., \& Austin, R.M. (2009). Histologic follow-up results in 662 patients with Pap test findings of atypical glandular cells: results from a large academic womens hospital laboratory employing sensitive screening methods, Gynecologic Oncology, Vol. 114, No. 3, (September 2009), pp. 383-389, ISSN 1095-6859 


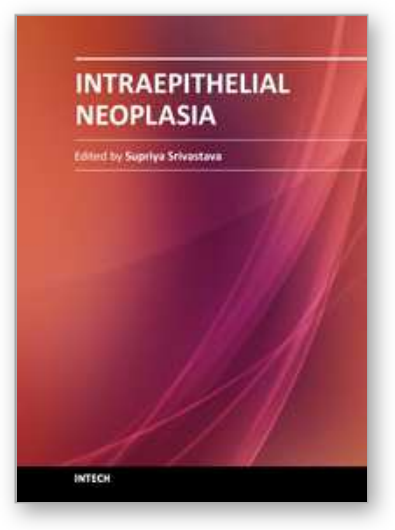

\author{
Intraepithelial Neoplasia \\ Edited by Dr. Supriya Srivastava
}

ISBN 978-953-307-987-5

Hard cover, 454 pages

Publisher InTech

Published online 08, February, 2012

Published in print edition February, 2012

The book "Intraepithelial neoplasia" is till date the most comprehensive book dedicated entirely to preinvasive lesions of the human body. Created and published with an aim of helping clinicians to not only diagnose but also understand the etiopathogenesis of the precursor lesions, the book also attempts to identify its molecular and genetic mechanisms. All of the chapters contain a considerable amount of new information, with an updated bibliographical list as well as the latest WHO classification of intraepithelial lesions that has been included wherever needed. The text has been updated according to the latest technical advances. This book can be described as concise, informative, logical and useful at all levels discussing thoroughly the invaluable role of molecular diagnostics and genetic mechanisms of the intraepithelial lesions. To make the materials easily digestive, the book is illustrated with colorful images.

\title{
How to reference
}

In order to correctly reference this scholarly work, feel free to copy and paste the following:

Chiung-Ru Lai, Chih-Yi Hsu and Anna Fen-Yau Li (2012). The Role of the Pap Smear Diagnosis: Atypical Glandular Cells (AGC), Intraepithelial Neoplasia, Dr. Supriya Srivastava (Ed.), ISBN: 978-953-307-987-5, InTech, Available from: http://www.intechopen.com/books/intraepithelial-neoplasia/the-role-of-the-pap-smeardiagnosis-atypical-glandular-cells-agc-

\section{INTECH}

open science | open minds

\author{
InTech Europe \\ University Campus STeP Ri \\ Slavka Krautzeka 83/A \\ 51000 Rijeka, Croatia \\ Phone: +385 (51) 770447 \\ Fax: +385 (51) 686166 \\ www.intechopen.com
}

\author{
InTech China \\ Unit 405, Office Block, Hotel Equatorial Shanghai \\ No.65, Yan An Road (West), Shanghai, 200040, China \\ 中国上海市延安西路65号上海国际贵都大饭店办公楼 405 单元 \\ Phone: +86-21-62489820 \\ Fax: +86-21-62489821
}


(C) 2012 The Author(s). Licensee IntechOpen. This is an open access article distributed under the terms of the Creative Commons Attribution 3.0 License, which permits unrestricted use, distribution, and reproduction in any medium, provided the original work is properly cited. 